\title{
Método colagem Bibi - o estudo da geração de alternativas aplicado a um projeto de embalagem de doce caseiro
}

\section{Bibi collage method - the alternative generation study applied to a homemade jam packaging project}

\author{
Gabriella Martins Porto ${ }^{[1]}$, \\ Andreia Bordini de Brito (orientadora) ${ }^{[2]}$
}

\begin{abstract}
Resumo: Este artigo apresenta considerações sobre trabalho de conclusão da autora, desenvolvido no curso de Design Gráfico da Universidade Federal de Pelotas, o qual aborda como tema central a análise e descrição do método de geração de alternativas denominado como método Colagem Bibi. Este, foi empregado para geração e criação de um modelo de embalagem da marca fictícia de doces caseiros: Chimia da Vó Vanda.

Palavras-chave: Processo projetual. Estratégia e inspiração. Geração de ideias.

Abstract: This article presents considerations done by the author as a graduation work, developed at the course of Graphic Design of the Federal University of Pelotas, which approach as the central theme, the analysis and description of alternative generation method called Bibi Collage method; which was used to generate and create a packaging model to the fictional homemade jam brand: Chimia da Vó Vanda.
\end{abstract}

Keywords: Design process. Strategy and inspiration. Idea generation. 


\section{INTRODUÇÃO}

Em planejamentos e projetos, a prática para cada ação envolve um código de desempenho. Tendo como exemplo os homens pré-históricos, para assegurar seu alimento através da caça, acompanhavam e cercavam a migração das manadas de animais com seus arcos, flechas e qualquer outra ferramenta utilizada no período. Pode-se dizer que o homem se comporta de forma metódica em seu dia-a-dia; desde as atividades mais triviais, até as mais complexas. Dentro do âmbito do design, o estudo de métodos é um hábito estruturado para o designer. Com isso, há um largo campo de possibilidades de métodos e inúmeras bibliografias que falam sobre esses; e é algo que está sempre sendo reinventado e aprimorado conforme o perfil do designer. É deveras um típico erro, talvez mais usual para com os iniciantes nessa carreira, julgar que o uso de um método se coloca de maneira restritiva aos caminhos passíveis de serem encontrados e explorados. Então, para isso, uma atividade otimista para esses designers é reconhecer e codificar essas etapas; isso visto que é imprescindível compreender a importância do uso apropriado de um método ao projetar como quando se é compreendida cada questão do projeto, o designer se torna mais apto a reconhecer todas as peças importantes de serem trabalhadas e também, reconhece com mais facilidade as resoluções mais apropriadas a serem tomadas.

Isso pode ser ocasionado de diversas maneiras, mas no caso do estudo desse artigo, a partir do momento que foi percebido um exercício de forma habitual, exercendo a mesma atividade sempre que precisava conceber um projeto gráfico, considerou-se a possibilidade de tornar esse um objeto de estudo pensando que poderia contribuir com outros designers. Essa prática habitual foi nomeada como método Colagem Bibi - nome o qual possui um aspecto lúdico, já que este é o apelido de infância da autora do método e desse estudo.

Portanto, o objetivo deste presente artigo é compreender o método Colagem Bibi, o qual está vinculado à fase de 
geração de ideias; e para além disso, o enfoque perpassa também pela utilização na sua forma prática, em um projeto de embalagem - utilizando uma marca fictícia, convindo somente na condição de um modelo.

\section{A REVISÃO DA LITERATURA}

As seções a seguir, apresentam a revisão de algumas literaturas em livros de design, contendo tópicos que foram importantes durante o processo do desenvolvimento do método Colagem Bibi.

\section{A GERAÇÃO DE ALTERNATIVAS}

A geração de alternativas é pertencente ao processo projetual situada no período intermediário do processo, e é onde de fato o produto começa a tomar forma e também o momento onde o designer considera todas as resultantes das problematizações feitas anteriormente durante o briefing, onde 0 mesmo decidiu os caminhos que pretende seguir no projeto; para então começar a moldar de forma prática o produto que será exposto e consumido pelo mercado posteriormente.

Ou seja, como etapa projetual, a geração de alternativas exige do designer conhecimentos prévios, como o domínio de técnicas de desenho e criação, além da identificação e da formalização de um problema, vinculado a determinadas necessidades e balizado por diferentes fatores - de ordem ergonômica, perceptiva, antropológica, tecnológica, econômica e ecológica (CALZA, Márlon Uliana; POLIDORO, Marina Bortoluz, 2015, apud REDIG, 2005).

Por conseguinte, a etapa de geração de alternativas é uma importante etapa em um trabalho de design, por mediar a primeira fase, onde ocorre a fundamentação do projeto com o resultado final, considerando os quesitos encontrados previamente e trabalhando de forma criativa e intuitiva. Além disso, é válido ressaltar que essa etapa não tem um número máximo, ou mínimo, de tentativas de geração das alternativas; podendo ser testadas pelo designer quantas ve- 
zes ele julgar necessário para originar um produto de design pertinente e de qualidade.

A fim de observar métodos já utilizados pelos designers, com a finalidade de sustentar o funcionamento do método Colagem Bibi, para além, evidentemente, da usual revisão literária que todo o pesquisador pratica em seus trabalhos, revisaremos dois métodos os quais se apresentam de forma consistente e também constante no meio de trabalho do design: o Brainstorming e o Método Delphi.

\section{O BRAINSTORMING}

Principiando o estudo, este método que é tão eficaz e adaptável em tantos gêneros de projetos, tanto de design como de outras áreas, o Brainstorming foi criado por um publicitário estadunidense chamado Alex Osborn, e é vista por muitas agências como uma dinâmica de grupo para dar cargo de resolver problemas ou desenvolver ideias inovadoras. Quanto a este, em um primeiro momento visa a quantidade e não qualidade - que é precedente a isso. Brainstorming, ou tempestade de ideias em português, é a ferramenta a qual se caracteriza por, através do pensamento livre sem limites, alcançar soluções improváveis. Isto se manifesta de forma que o brainstromer ${ }^{[3]}$ faz o uso do conjunto das ideias imaginativas obtidas pelos stormers ${ }^{[4]}$, e então, as combina e recombina para que estas se tornem atividades mais palpáveis para exercer seu papel de solucionar o problema de design. De outro modo, o brainstorming é uma espécie de dinâmica em grupo, ou individual, o qual estimula o pensamento criativo através da atividade de gerar ideias e pensamentos abundantemente e, dessa forma, resolver os problemas e o desenvolvimento de ideias inovadoras.

Existem alguns princípios básicos que ajudam a sessão de brainstorming ficar mais organizada e que auxilia na hora da geração de ideias; mais precisamente cinco princípios e uma sugestão (CIARLINI, Juliana; 2014). A primeira atenta-se a esquecer qualquer tipo de julgamento. As ideias expostas
[18] Aquele que conduz o processo de brainstorming.

[19] Aquelas que fazem parte da equipe. 
por um participante da equipe são tão importantes quanto as ideias de um outro. Por mais que o primeiro não concorde com o segundo, por exemplo, esse não é o momento de fazer críticas ou censuras. Com isso, outro princípio levantado é em relação a igualdade de oportunidade, o qual possui valores relacionados ao anterior, contudo, este ainda considera a situação onde o designer precisa trabalhar em uma equipe que é integrada também por profissionais de outras áreas. Tendo essa situação em vista, todos devem sempre lembrar que fazem parte de uma mesma equipe e todos têm o direito de apresentar as ideias para o grupo do mesmo modo. 0 terceiro, fala sobre focar na quantidade. Como dito antecipadamente, no início o brainstorming visa uma grande quantidade de ideias; por isso o designer não deve se conter e procurar já de início filtrar as ideias. Esse é o momento de gerar o maior número de alternativas. O quarto princípio diz respeito ao "entire freedom" (completa liberdade, tradução livre) - como coloca a autora. O significado disso está no argumento de que seja qual for a ideia, essa é bem vinda. Como o brainstorming ocorre após identificado o problema de design, nesta etapa há um direcionamento do caminho exigido, portanto, a ideia mais simples pode surtir efeito e ser a base para uma solução. Por último, temos o quinto princípio: mudança e recombinação. Fazer combinações distintas, pode resultar na construção de melhores ideias. Novas conexões muitas vezes são ascendentes a resultados interessantes e que solucionam o problema.

Contudo, é imprescindível esclarecer que essa estrutura vista até esse momento da conceituação do brainstorming é somente uma das formas de aplicação dessa técnica. Essa é a denominada brainstorming classic. As outras formas de se trabalhar essa técnica são variações as quais julga-se desnecessário explanar aqui por não apresentarem vastas distinções no foco projetual. 


\section{BRAINSTORMANDO}

Figura 1 - Os 5 princípios básicos do brainstorming e 1 sugestão. Fonte: Elaborado pela autora (2019)<smiles>[C+]1C=CC=C1</smiles>

ESTIPULE O TEMPO QUE DESEJA GASTAR

ESQUECER QUALQUER JULGAMENTO

IGUALDADE DE OPORTUNIDADE

FOCAR NA QUANTIDADE

ENTIRE FREEDOM:

TODA IDEIA É BEM-VINDA

MUDANÇA E RECOMBINAÇÃO

\section{O MÉTODO DELPHI}

Uma outra geração de alternativa, como listada anteriormente, que será objeto de estudo é o chamado Método Delphi. Seu nome provém do "Oráculo de Delphos"[5] e foi desenvolvido na década de 1950 pelos órgãos de defesa dos Estados Unidos. Esse método tem como principal objetivo facilitar e melhorar as tomadas de decisões, isso dado a uma característica incomum: não exige interação presencial. Essa geração de alternativa, usualmente se procede por meio de um questionário, o qual é respondido por todo os designers participantes de forma sequencial, onde o segundo resume a resposta do primeiro e assim gradativamente, a fim de construir uma espécie de resposta coletiva. A cada "rodada", os resul-
[20] Considerado mais importante centro religioso da cidade de Delfos, na Grécia antiga (8 a.c. e 2 a.c.), por ser procurado por diversas pessoas que supostamente recebiam previsões sobre o futuro, conselhos e orientações. (SUPER INTERESSANTE. 0 que era 0 Oráculo de Delfos?. Disponível em: <https://bit.ly/3nzJWEA> Acesso em: 14 de maio de 2019). 
tados são analisados por pesquisadores, os quais observam as tendências e as opiniões dissonantes, as justificativas e outros, para reunir essas informações e então as reenviar ao grupo. Com isso, os participantes têm a oportunidade de alterar, aperfeiçoar ou até mesmo, defender as suas respostas; enviando-as de volta aos pesquisadores que por sua vez, elaboram um novo questionário, onde o processo se repete até o momento em que se entra em um consenso, em vista que a cada rodada, os pesquisadores também expõe suas opiniões. No método Delphi é suposto que as pessoas partilhem as suas premissas e não apenas as suas conclusões. (MARQUES, J. B. V., FREITAS, D. D. apud Facione, 1990, p. 55).

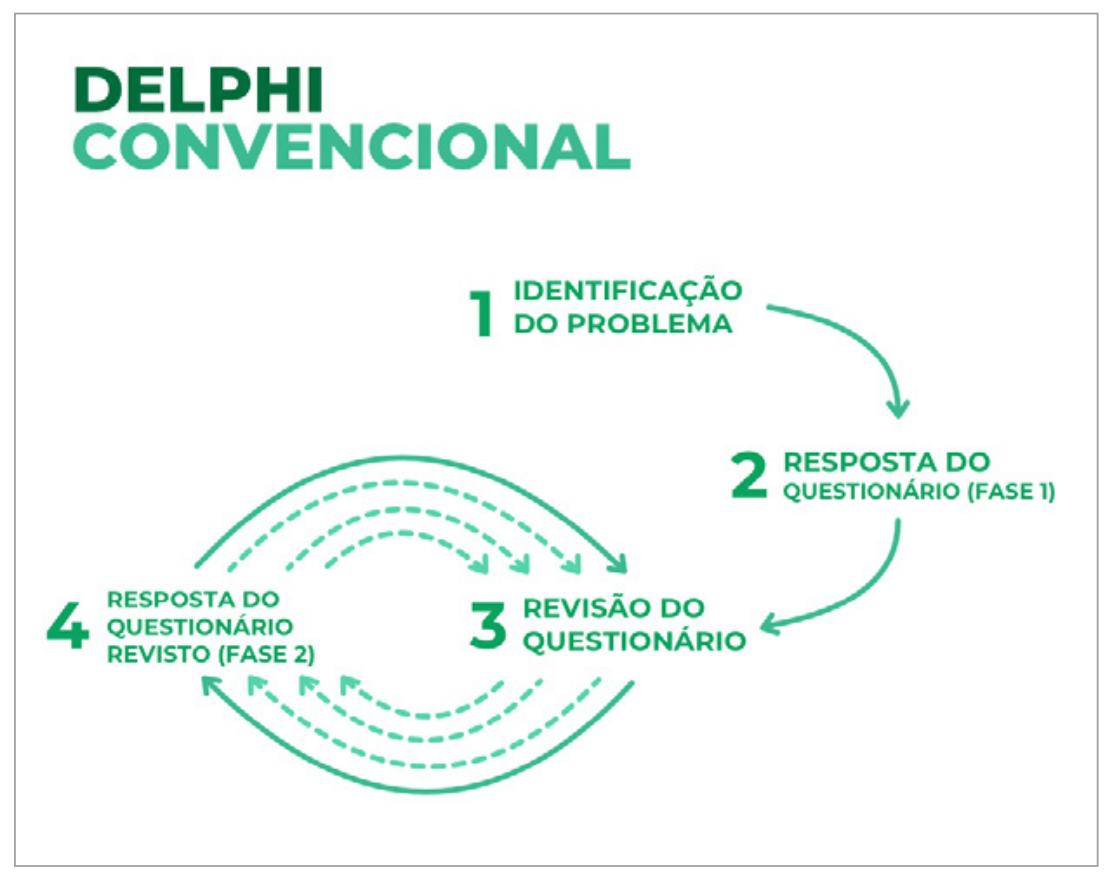

Há três tipologias do estudo Delphi descritas na literatura - o convencional, o normativo e o Policy Delphi.

O convencional, é o qual o tem como objetivo procurar a opinião do grupo a respeito de um assunto embasado em um tipo de previsão. O normativo, no entanto, estabelece objetivos com base no que se deseja que vá ocorrer, e não em
Figura 2 - Esquema do processo Método Delphi. Fonte: Elaborado pela autora (2019) 
previsões do que ocorrerá. O Policy Delphi, normalmente procura gerar pontos de vista opostos sobre um assunto específico, geralmente envolvendo questões políticas e sua implementação. Se opondo diretamente ao Delphi convencional, esse foca justamente nas divergências ao invés do consenso.

\section{O BRIEFING FICTÍCIO}

Como documentado anteriormente, neste presente artigo, será concebida uma embalagem como um exemplo do emprego, na prática, do método Colagem Bibi. Com isso, ao longo do desenvolvimento desse artigo, percebeu-se que é mais eficiente, apresentar o briefing dessa embalagem fictícia em um primeiro momento para após isso, ser apresentado a estrutura da Colagem Bibi, porque do contrário, além de não ser possível assegurar a compreensão total do texto, o mesmo poderia se desdobrar deveras repetitivo.

Com essas declarações, portanto, o desenrolamento do briefing se dá por respondermos algumas questões. Para este modo, será suposto que uma senhora idosa, que se chama Vanda é a cliente que demanda da produção de embalagens de doce caseiro, feito a partir das frutas maçã, figo e abóbora, feito a partir de uma prática cultural da descendência de alemães onde a receita foi aprendida no âmbito familiar, passada entre gerações, e que este doce é produzido em seu próprio domicílio.

Fazendo o uso dessas informações, para melhor entendimento destas, será utilizado um modelo proposto por Noble e Bestley (2005) o qual eles fragmentam o briefing em um esquema separado em três etapas: o campo de estudo, que se caracteriza pela disposição inicial das características das funções e que responde às questões mais básicas. Neste caso então, a função se caracteriza por conceber uma embalagem de doce de fruta caseiro, o qual é produzido em casa por uma única cozinheira, utilizando as frutas do próprio pomar e sob encomenda. Portanto, estima-se que os custos devem cobrir a despesa com embalagens reservas, para cada sabor da fru- 
ta, considerando todos os materiais e os elementos gráficos impressos, gás de fogão e o transporte do produto para o ponto de venda ou a entrega para o consumidor. A segunda parte da fragmentação do briefing, está dentro do foco projetual, onde é dividido em dois sub ramos, denominados como $<$ context-definition $>^{[6]}$ o qual responde essas perguntas mais específicas como tipo de público alvo, e o <context-experiment $>\left[{ }^{[7]}\right.$ é designado a testes, melhorias e experimentações para quando o produto já está no mercado. Dessa forma, o que nos interessa nesse momento, é que <context-definition> aponta que a embalagem é para o público que possui o hábito de consumir chimia e que está familiarizado com o termo, no entanto, a embalagem ainda deve ser objetiva e esclarecendo desde o princípio o produto que é, a fim de não descartar outros públicos. Por último, o briefing ainda é fragmentado em uma última parte, a chamada metodologia de execução, que é a parte que possui maior ligação prática com o método de geração de ideias utilizado (que neste caso é a Colagem Bibi), nessa vamos estabelecer o caminho que o designer deve considerar para elaborar a comunicação visual, o qual aqui deverá ser de um produto com características que evoquem o artesanal e caseiro.

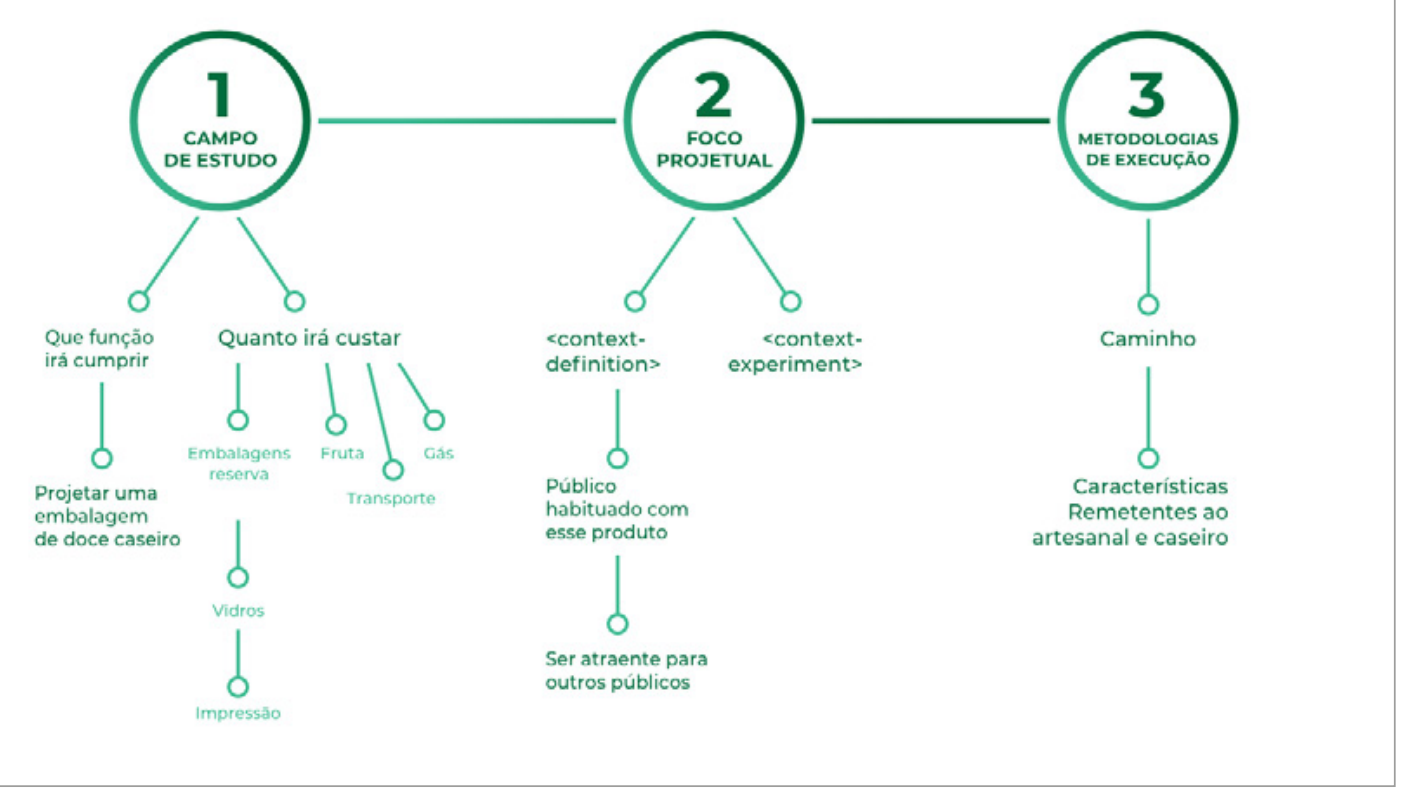

[21] Em tradução livre, significa contexto e definição. No entanto, entendeu-se que não seria necessário traduzi-lo.

[22] Em tradução livre, significa contexto e experimentação.
Figura 4-Organograma da estrutura do briefing a partir da proposta de Noble e Bestley. Fonte: Elaborado pela autora (2019). 
Como um último requisito antes de ser iniciado a demonstração do método Colagem Bibi, abaixo será apresentado um esquema de produzido a partir de uma breve análise taxonômica do mercado, produto e consumidor; utilizando como fonte a sites de busca como o Google e o Pinterest.

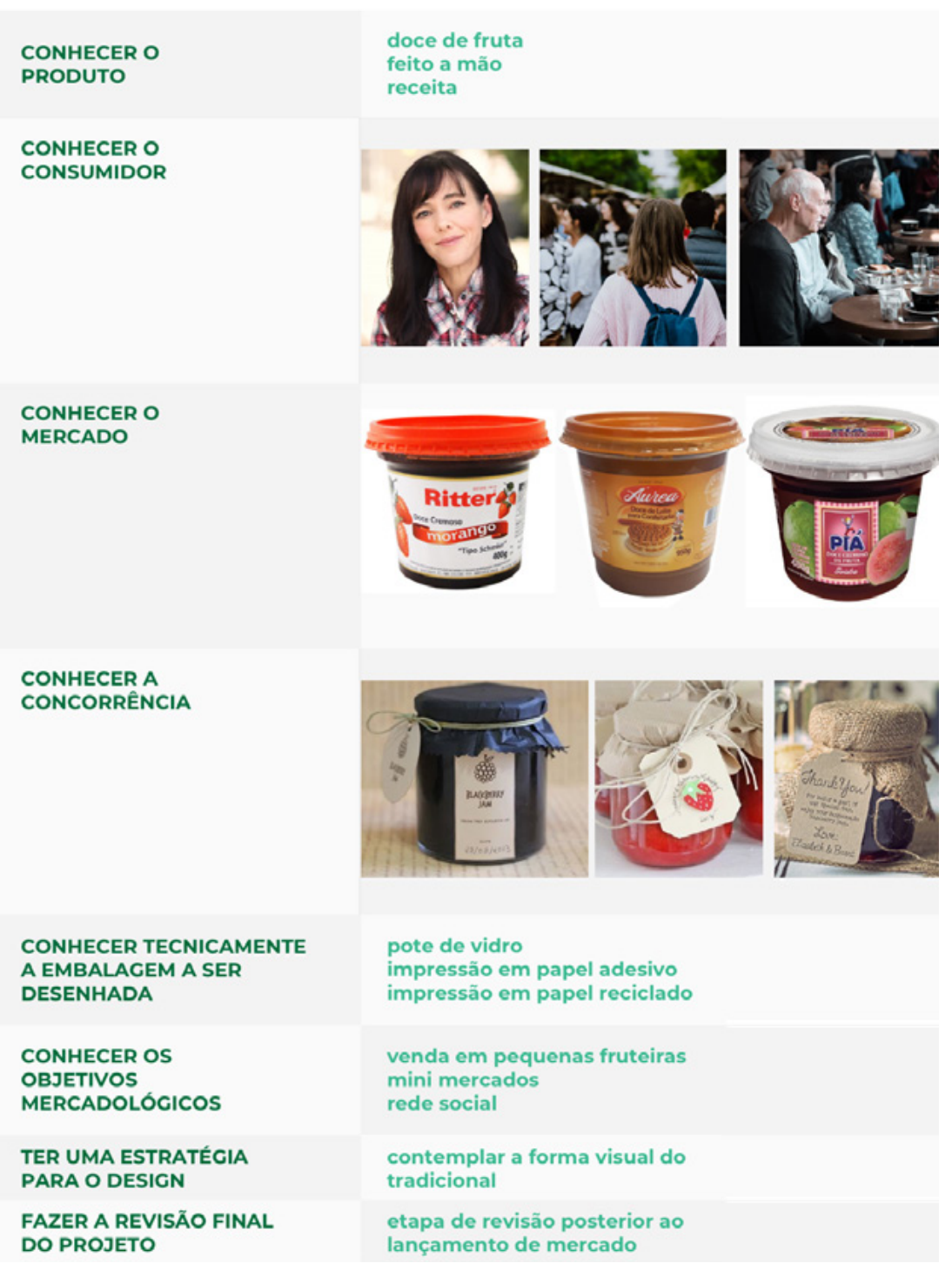

Tabela 1 - Análise taxonômica do mercado, produto e consumidor. Fonte: Elaborado pela autora (2019). 


\section{A COLAGEM BIBI}

A fim de fazer uma contextualização dessa geração de ideias que irá ser analisado e, com a finalidade de reconhecimento do método, este foi denominado "Colagem Bibi", por ser o apelido da autora deste trabalho. Este método, se apresenta como uma colagem visual a partir da coleta de informações que inspiram os caminhos a serem seguidos. Chamado de colagem visual em razão dos elementos estarem sobrepostos, como se tivessem sidos recortados e colados. A Colagem Bibi configura um tipo de mockup; o qual determina os grafismos que serão utilizados e os espaços a serem ocupados no processo projetual da embalagem. Na intenção desse contexto facilitar a visualização mental de como essa geração de ideias funciona, pode-se dizer, de forma imaginativa e comparativa, que o método se dá através do resultado da junção do wireframe hifi[8] com o mockup ${ }^{[9]}$.

O método Colagem Bibi, se inicia com o feitio de compreender o briefing, considerando todos os dados levantados no capítulo anterior, o primeiro passo foi transcrever utilizando papel e caneta, esses dados. É possível que essa etapa seja descartada por pessoas que não possuem o mesmo afinco com a materialidade do papel e caneta.

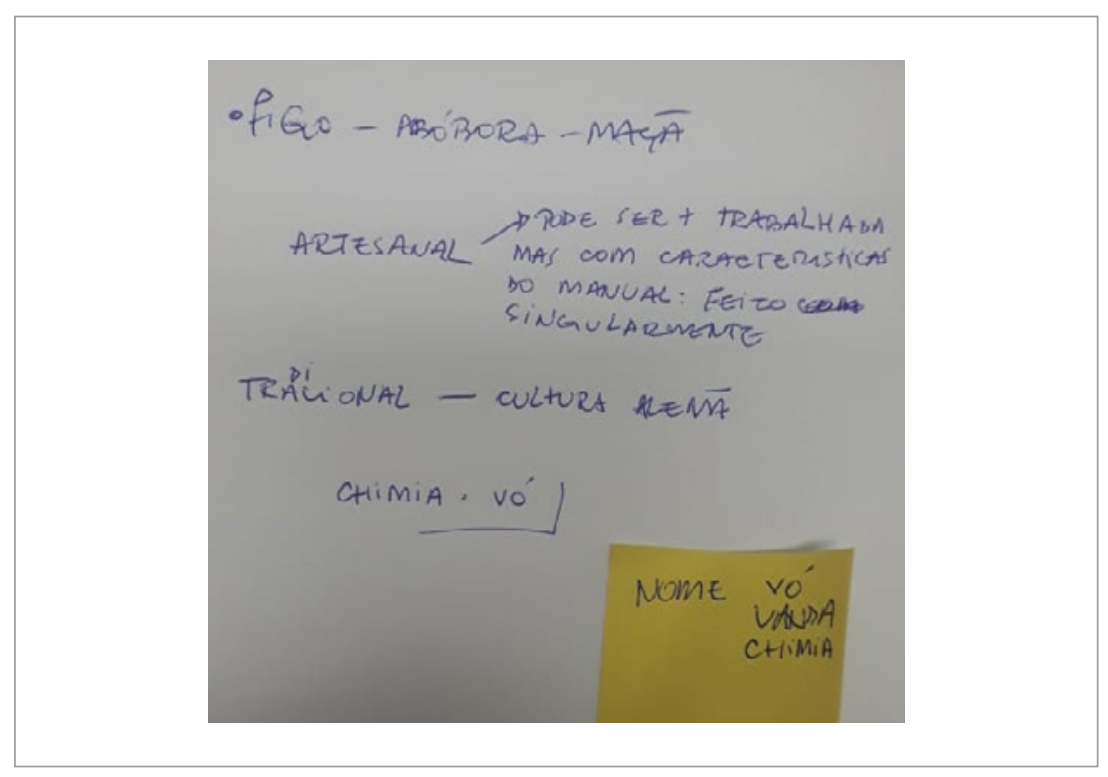

[23] Wireframe high fidelity são protótipos de representação do produto final, constantemente utilizados em projetos de design digital como na elaboração de sites. (JUST IN MIND. Low fidelity vs high fidelity wireframes: what's the difference?. Disponível em: <https://bit.ly/3nivIrI> Acesso em: 27 de junho de 2019)

[24] É um modelo em escala usado para demonstração da ideia pretendida pelos designers, sem ser necessário produzir um protótipo material do projeto. (WIKIPÉDIA. Mockup. Disponível em: $<$ https://bit.ly/34g7tTo > Acesso em: 27 de junho de 2019)

Figura 5 - Fotografia dados revistos. Fonte: Acervo da autora. 
Posteriormente, se acessa a alguma plataforma de inspiração a partir do navegador, buscando produtos similares com o que se deseja produzir.

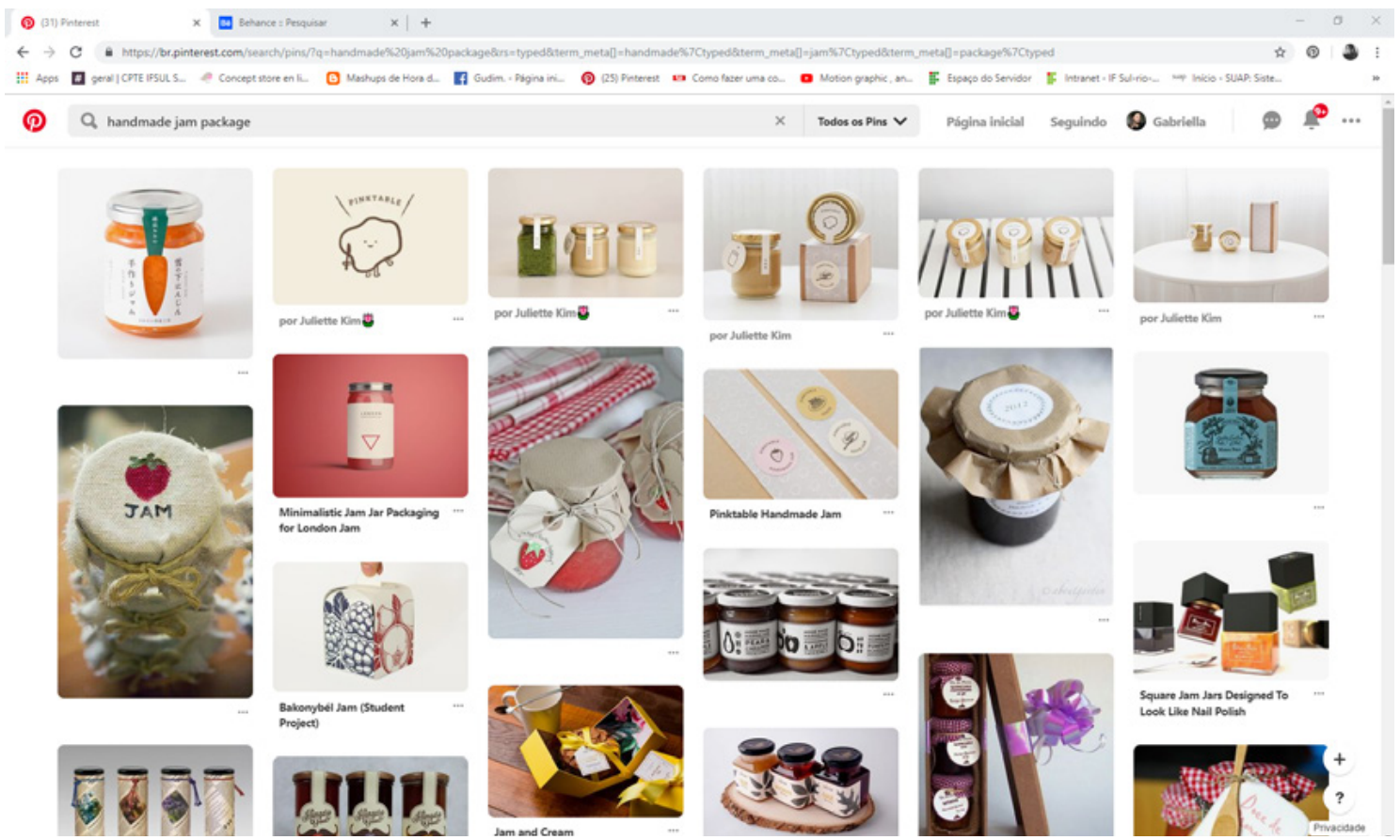

Figura 6 - Print Screen Pinterest. Fonte: Acervo da autora.

Figura 7 - Print Screen Behance. Fonte: Acervo da autora.

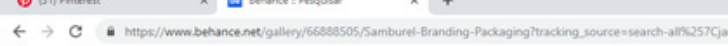

(๑)

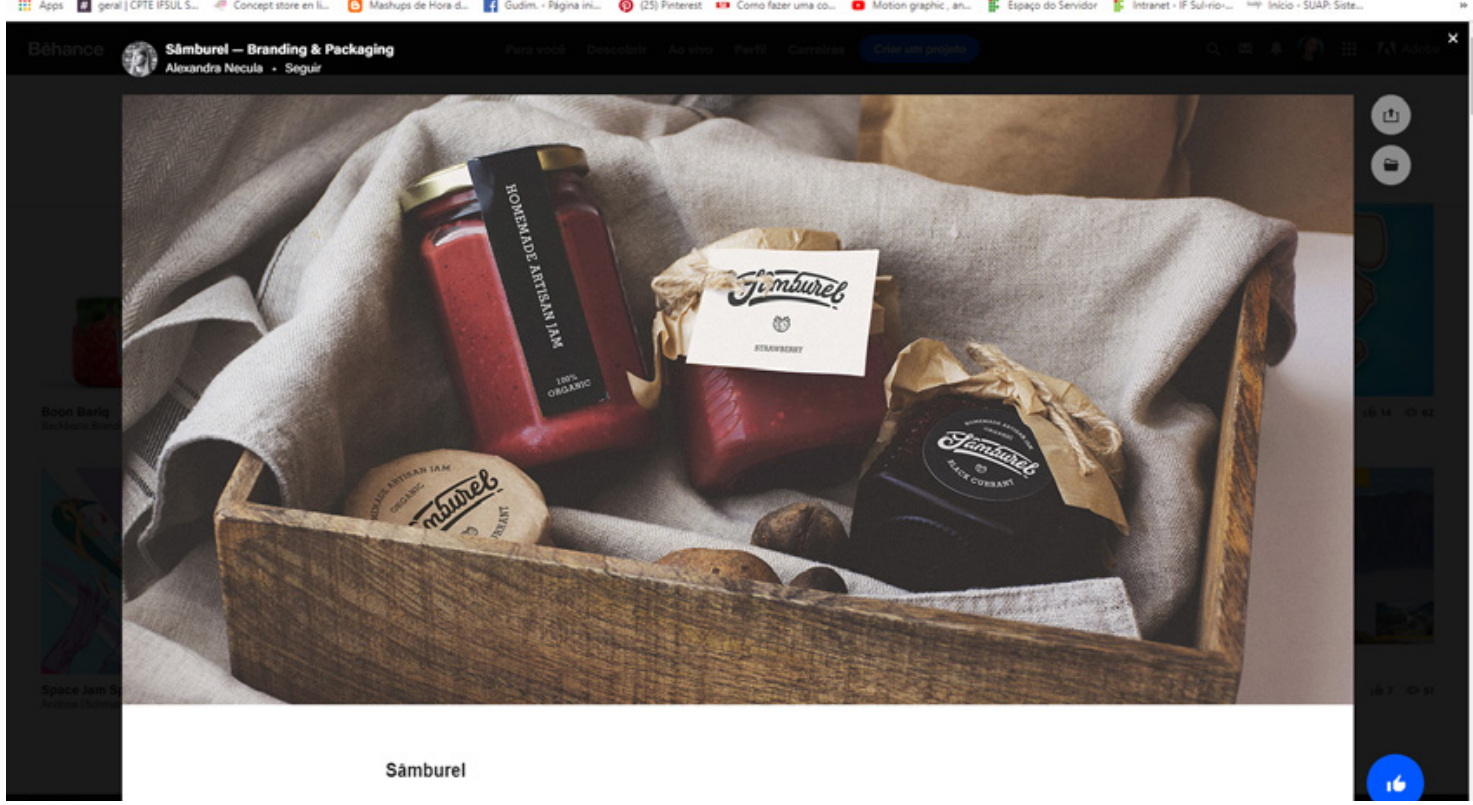


Após esse tempo de estudo e buscando inspiração, é hora de abrir o software desejado. Neste caso foi o Adobe Illustrator CS6. Com o Illustrator aberto, criou-se um moodboard ${ }^{[10]}$.

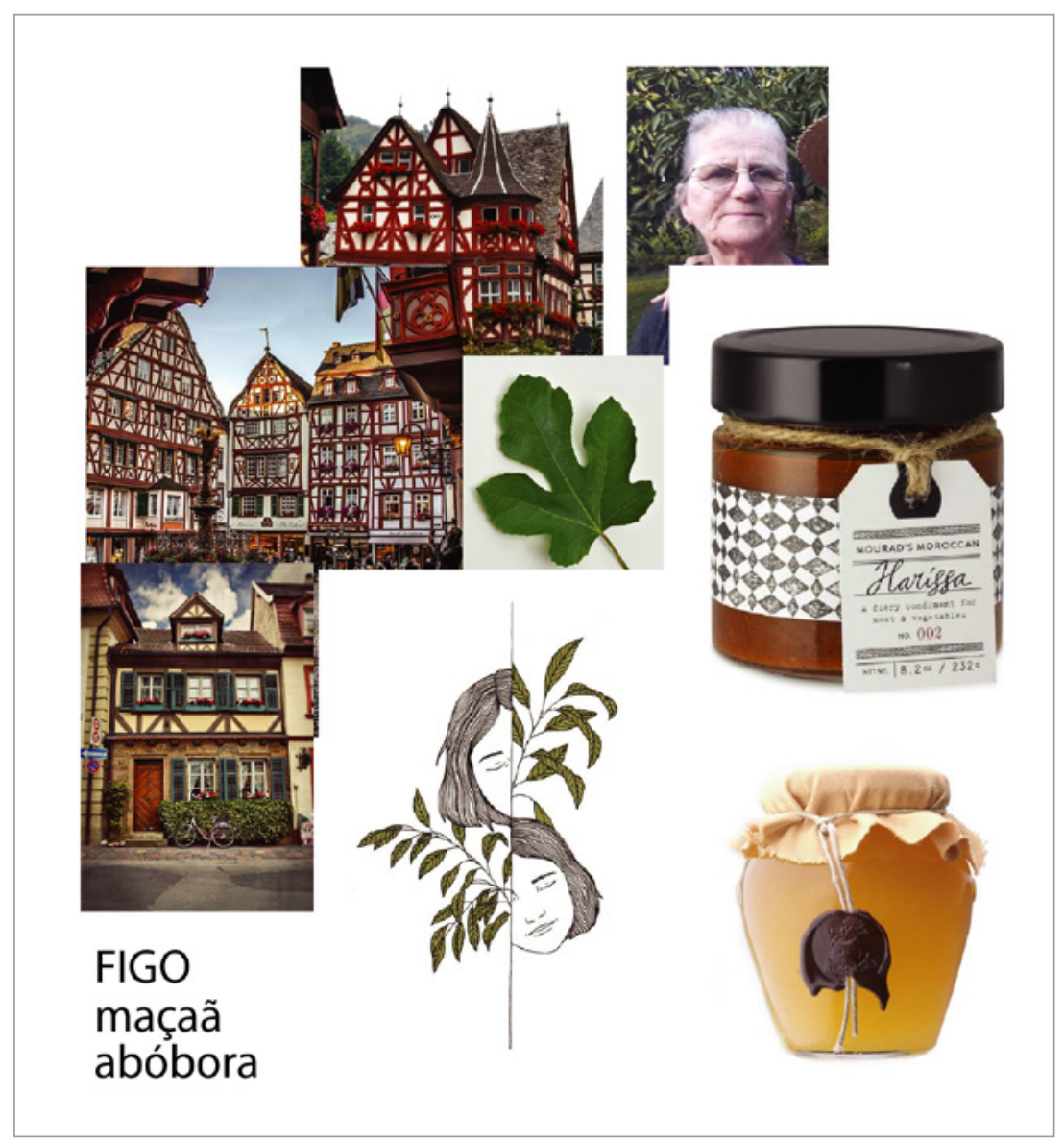

[25] Em tradução livre para o português "quadro de atmosfera", é amplamente utilizados por designers de diversas áreas com o intuito de organizar e traduzir visualmente uma ideia. (MEU ESTILO DECOR. Você sabe o que é Moodboard?. Disponível em: <https://bit. ly/3nnXXFw> Acesso em: 19 de novembro de 2019)

Figura 8 - Moodboard Colagem Bibi. Fonte: Acervo da autora.

Com o moodboard feito, percebeu-se que antes de começar a montar a Colagem Bibi, era melhor primeiro criar o logotipo e no nome da marca. Isso em razão que, sem o logotipo, ficaria complicado planejar os espaços a ocupar e prever suas dimensões para aplicá-lo, além de alocar as outras informações e elementos gráficos. Então, foram executados os dois últimos passos mostrados acima. 


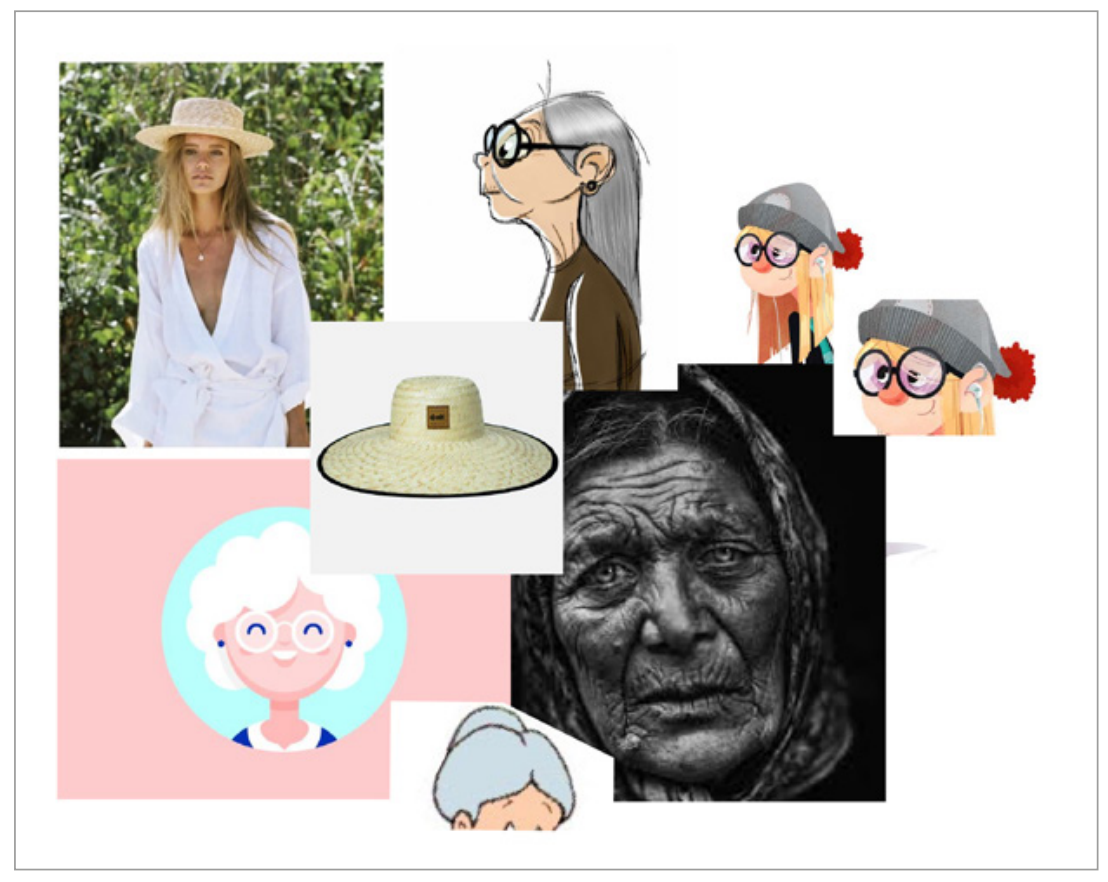

Figura 9 - Print Screen Moodboard Logotipo. Fonte: Acervo da autora.

Seguindo as referências deste, o primeiro passo foi produzir o desenho de uma pessoa idosa, o propósito do logo. Por ser uma senhora que produz os doces a partir das frutas de seu próprio pomar, empregou-se o desenho de um chapéu sobre sua cabeça, pelo lúdico ao imaginar essa persona indo colher os frutos das árvores sob o sol.

A tipografia, do logotipo, expressa: Chimia (da) Vó Vanda. O primeiro, reúne dois que compõem o principal ponto-conceito da marca: costume e tradição. Com isso, a escrita "chimia" - ao invés de doce ou geléia - agrega justamente no resgate de um costume, por ser uma palavra aportuguesada e também, apela a um nicho de mercado, que são aqueles cujo possuem costume de consumir esse tipo de produto. Agora, o "Vó Vanda" apesar de possuir, de fato um nome, representa mais um conceito do que uma designação. $O$ fato de estar escrito o termo "Vó", trás uma ideia de qualidade, por termos essa ideia da relação de avós com comida, é claro que se tem algumas exceções e que essa é uma ideia muito subjetiva e de forte ligação e dependência com a vivência de cada 
um, mas ainda assim, existe como um conhecimento geral de questões que abraçam esse ideal de avós que cozinham. 0 Vanda, evidentemente, se apresenta por ser o nome original de quem inspirou esse trabalho, além disso, outro fator considerado foi a simetria do nome que, junto da palavra Vó, soa de forma harmônica e agradável.

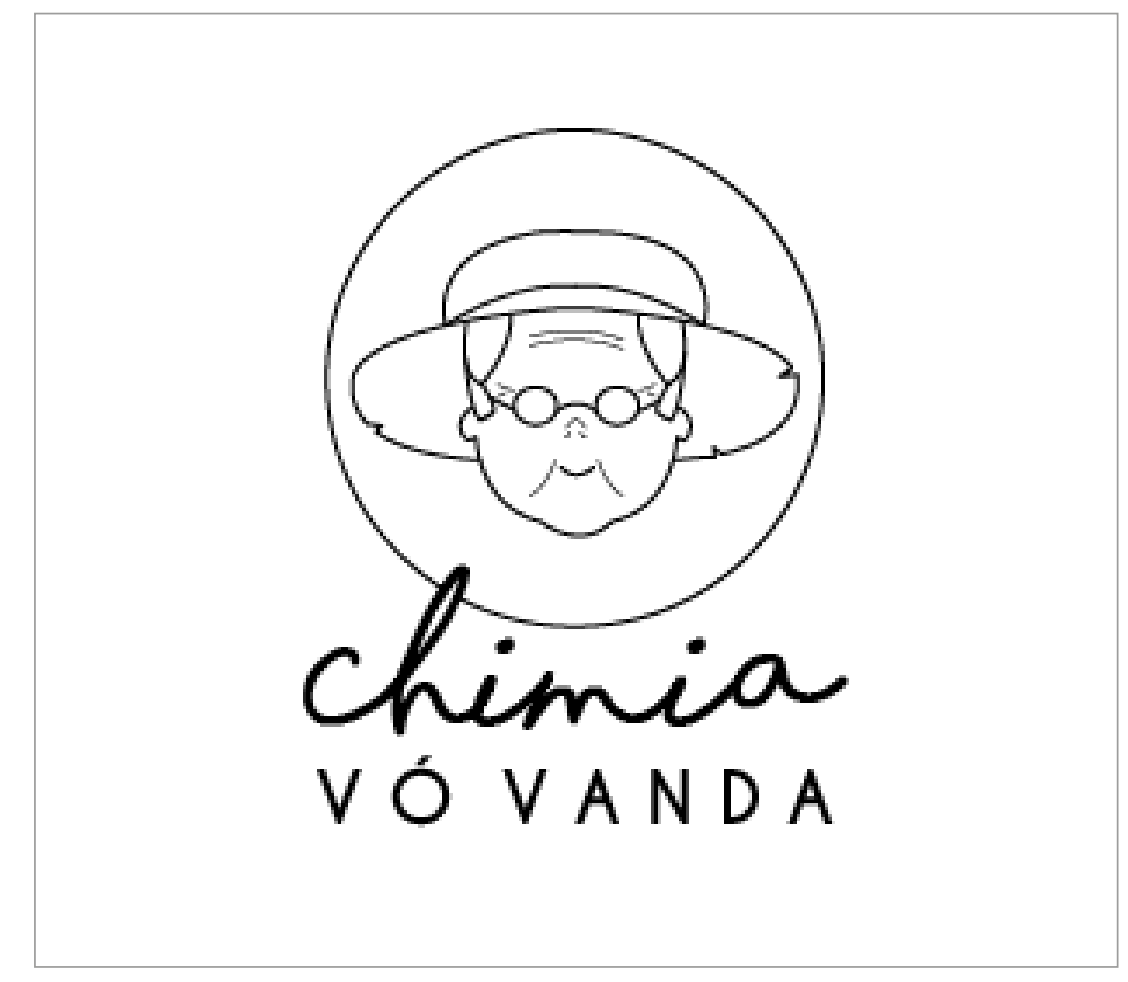

Figura 10 - Logotipo Marca. Fonte: Acervo da autora.

Como consideração final, é válido ressaltar o círculo que envolve o logo, com o intuito de assegurar a divisão igual de peso na composição da marca.

Combinando tipografia que aparenta ter sido manuscrita com uma tipografia bastonada. A primeira fonte, refere-se a proximidade do consumidor com o produto, visto que a fonte escolhida é orgânica e imita a escrita à mão, tornando o produto, como forma de dizer, mais humano e individual. Já a segunda, preza pela legibilidade do nome, o que além disso, também tornou a composição harmônica e equilibrada. 
abcdefghijklm

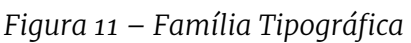

Shorelines Script Bold.

Fonte: Pinterest (2019).

nopqrsteoveryz

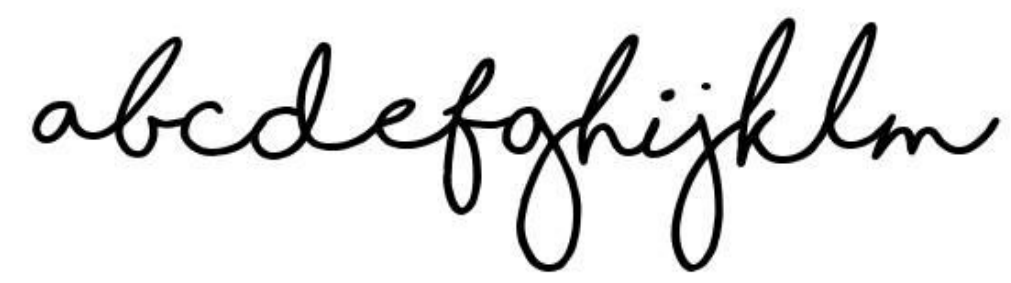

nopgeturwaxyz

$0123456789 ! ?$ \#

abcolefghijklmnopgrstuvwxyz

ABCDEFCHIJKLMNOPQRSTUVUXYZ

0123456789 (!@\#\$\%E.,?:;) 
Com o logotipo finalizado, resta finalmente iniciar a montagem da Colagem Bibi. Como mencionado anteriormente, este é substancialmente um tipo de wireframe misto com mockup, desse modo e, com o moodboard dominando o campo de visão, é hora de selecionarmos os elementos que irão ilustrar quais os caminhos que o designer irá aderir. Conduzindo de maneira objetiva a narrativa desse processo, primeiro buscou-se no Google Imagens uma fotografia do vidro que irá servir como invólucro da chimia. Com isso, considerando o moodboard e as ideias criativas, elaborou-se o rótulo da embalagem.

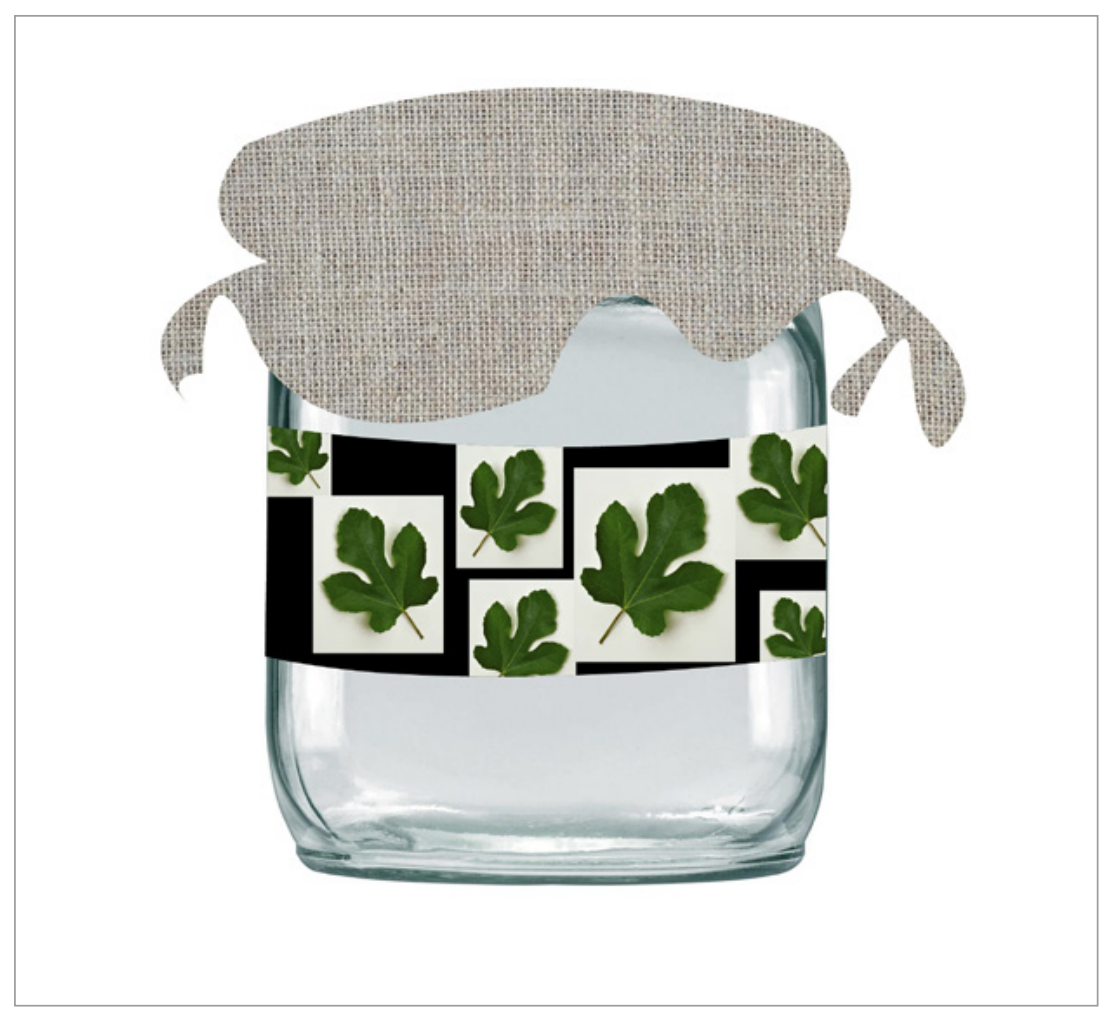

Figura 13 - Print Screen Rótulo Colagem Bibi. Fonte: Acervo da Autora.

O rótulo apresentará com uma ilustração vetorial, as folhas do ramo da fruta correspondente ao sabor daquela chimia. Para o desenho se preocupou em transmitir algum nível de realismo, ainda que seja apenas represen- 
tado pelo contorno das folhas. A cor verde foi utilizada de maneira lúdica, pois como as ilustrações são folhas, optou-se por selecionar essa cor.

Tendo em vista que esse trabalho aspira apresentar embalagens para as chimias de sabor figo, abóbora e maçã, o rótulo de cada uma destas, respectivamente se manifestam como:
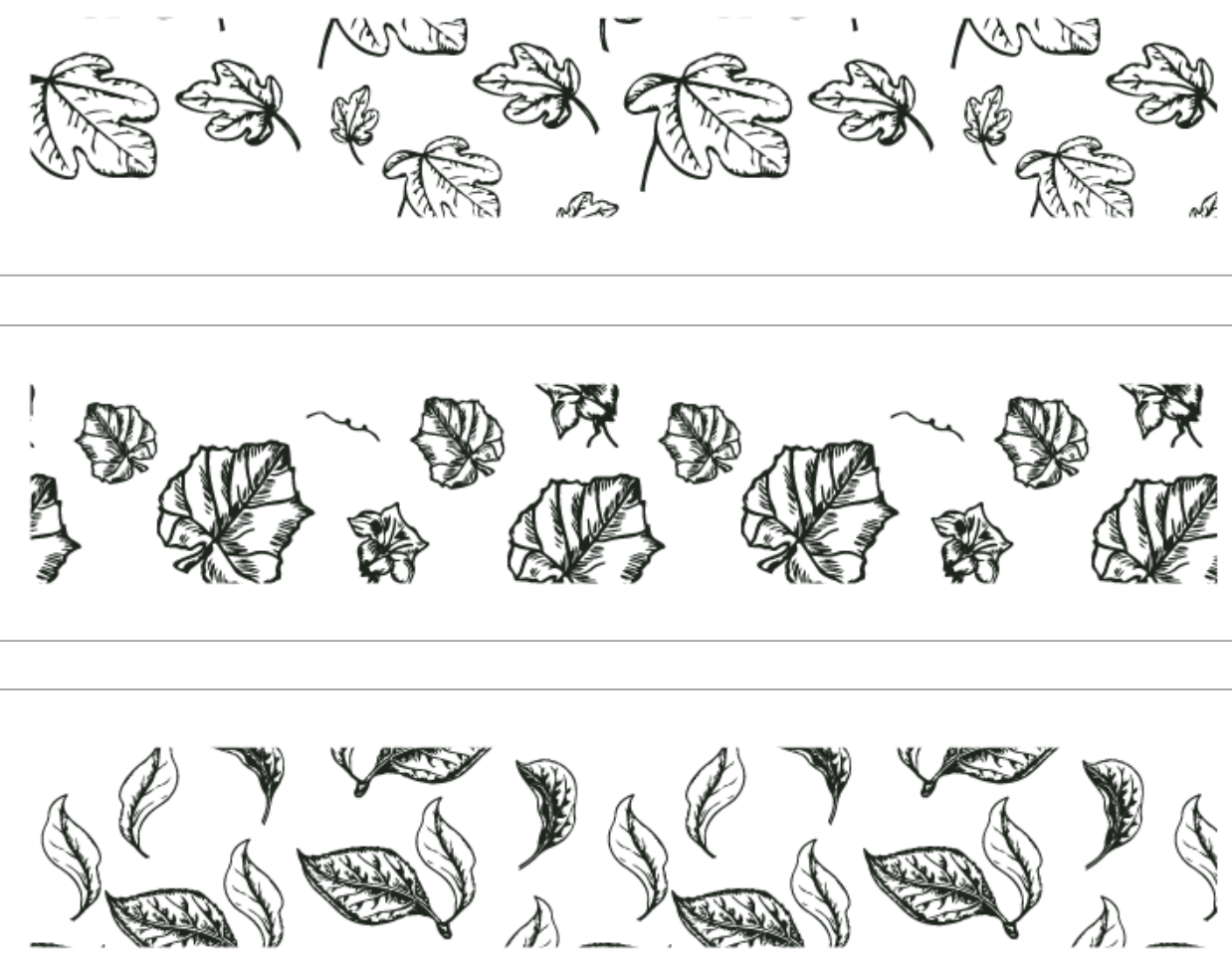

Assim sendo, se faz conveniente mencionar aqui que os doces artesanais não requerem especificações nutricionais e outras informações além da data de validade; diferente dos produzidos em grande remessa em fábricas ${ }^{[11]}$.

Neste ponto, com o rótulo apresentando uma padronagem com as folhas da fruta em particular, percebeu-se que a tampa reservava espaço suficiente para suportar a marca.
Figura 14 - Imagem Rótulo da Chimia de Figo. Fonte: Acervo da Autora.

Figura 15 - Imagem Rótulo da Chimia de Abóbora. Fonte: Acervo da Autora.

Figura 16 - Imagem Rótulo da Chimia de Maçã. Fonte: Acervo da Autora.

[26] Existe uma lista exposta pela Anvisa dos alimentos que não possuem obrigatoriedade da rotulagem nutricional. No caso da chimia, este se caracteriza como Aditivos alimentares e coadjuvantes de tecnologia, o qual é um dos tipos que não necessitam dessa rotulagem. (ANVISA. Perguntas View Rotulagem Nutricional. Disponível em: <https://bit.ly/3ai3J7Q> Acesso em: 15 de julho de 2019) . 
No momento da composição da análise da concorrência, visto como as embalagens são encontradas no mercado, imediatamente se pretendeu também utilizar um tecido que envolvesse a tampa, a fim de trazer uma característica comum de identificação do produto; para além de outros elementos. Para então inserir a marca na tampa, não se considerou fazer impressão sobre o tecido, pelas questões projetuais vistas previamente. Portanto, a solução para esse problema, foi utilizar a marca carimbada sobre tecido que cerca a tampa. A escolha do carimbo foi bastante pertinente, tendo em vista o tempo de vida útil ser perene, e ainda, fortalece o conceito de trabalho artesanal.

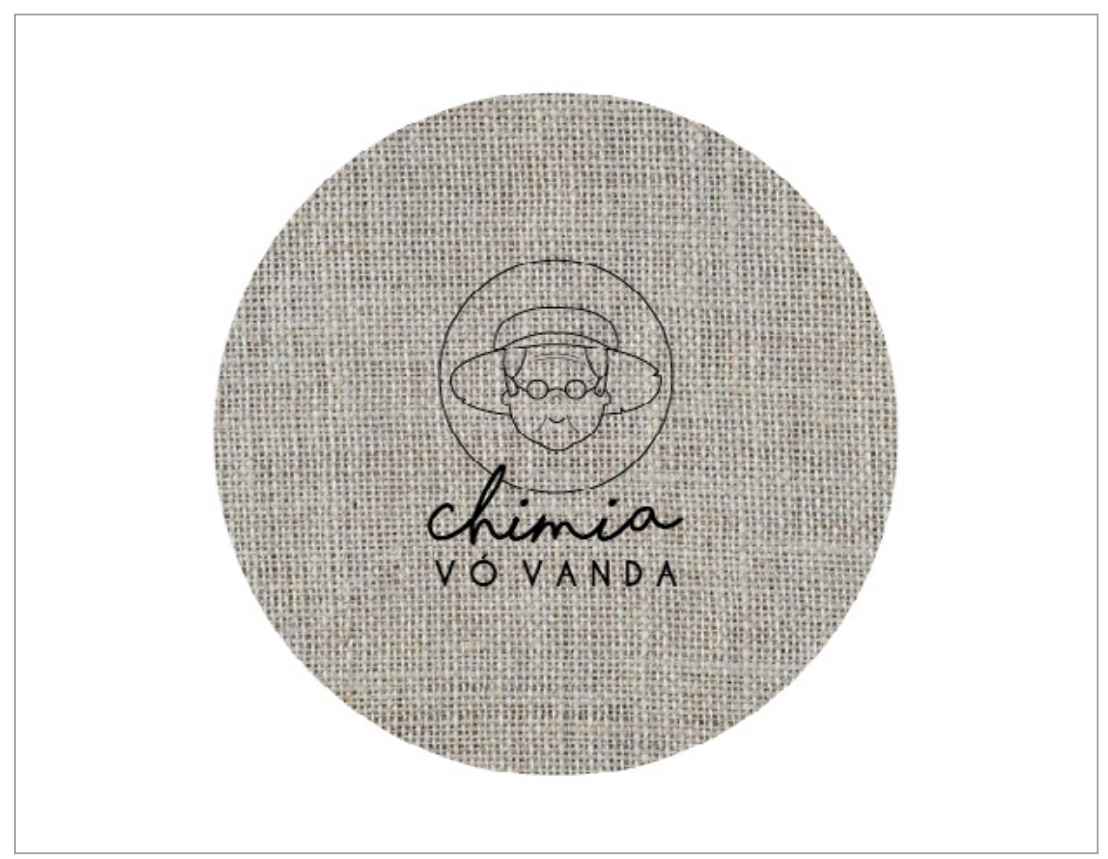

O tecido utilizado é do tipo que se usa para fazer bordado[12], em cor off white ${ }^{[13]}$ para regular com o utilizado no mercado. Como não optou por se utilizar a cor branca pura, o rótulo nesse momento passou a ter as ilustrações das folhas em verde sobre fundo preto.
Figura 17 - Print Screen Tampa Colagem Bibi. Fonte: Acervo da Autora.

[27] Chamado de Etamine. Produzido com $100 \%$ de algodão. (CENTERFABRIL. Tecido Etamine Micro para Bordar 1623 Marfim Larg 1,40mt $100 \%$ algodão Karsten 195gr/m2 Disponível em: <https://bit.ly/37opLEh> Acesso em: 03 de julho de 2019).

[28] O off-white não é um branco totalmente branco. Ele é quase um branco. Alguns o definem como um branco envelhecido, outros como um branco "sujinho". Essa tonalidade é uma variação do branco para o bege. (CORAL. A vez do off-white. Disponível em: <https://bit.ly/30XUbTQ> Acesso em: 03 de julho de 2019). 


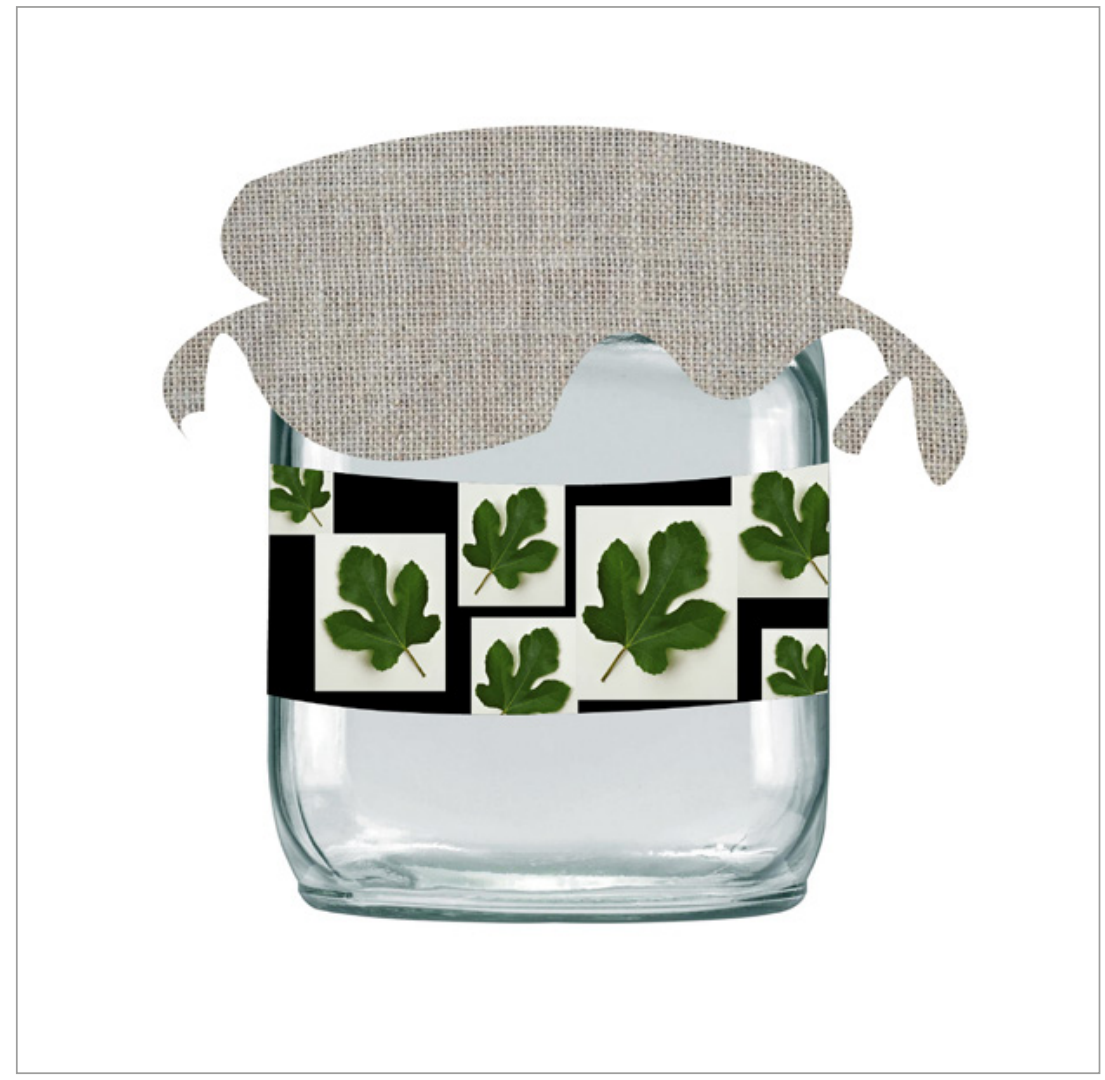

Por último, para indicar a data de validade, considerou-se utilizar uma etiqueta sustentada por uma fita que se parece com uma corda, produzida a partir do sisal[14]. Esse também é uma característica particular desse tipo de embalagem. Observou-se que a etiqueta poderia ter um propósito além da função de informar a validade, também ser um elemento ornamental. Desse modo, foi arquitetado em forma de elipse uma etiqueta em forma de cartão, trazendo outras frases informacionais.

A partir do boneco, se planejou uma frase que indicasse que o produto é feito de forma artesanal, considerando todos os conceitos desenvolvidos ao longo do projeto. Com isso, a frase criada foi "artesanalmente, com amor de vó". Utilizando a estrutura e tipografias do logotipo, a frase se apresenta da seguinte forma:
Figura 18 - Print Screen Tampa e Rótulo Colagem Bibi. Fonte: Acervo da Autora.

[29] Planta originária da América Central, utilizada para fins comerciais da área têxtil. (WIKIPÉDIA. Sisal. Disponível em: <https://bit.ly/2KsOBcW> Acesso em: 03 de julho de 2019). 


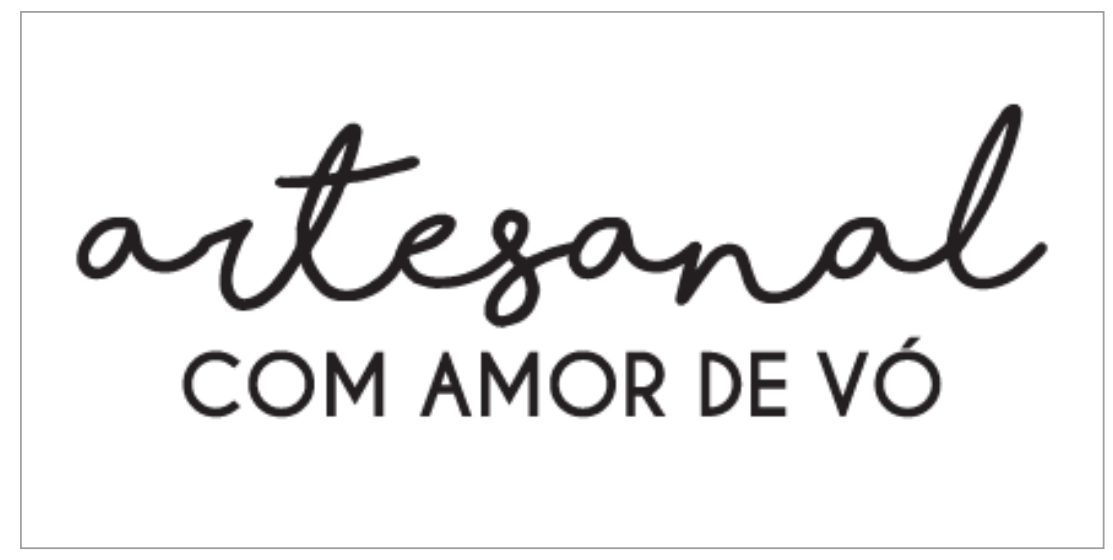

Figura 19 - Imagem Etiqueta frontal. Fonte: Acervo da Autora.

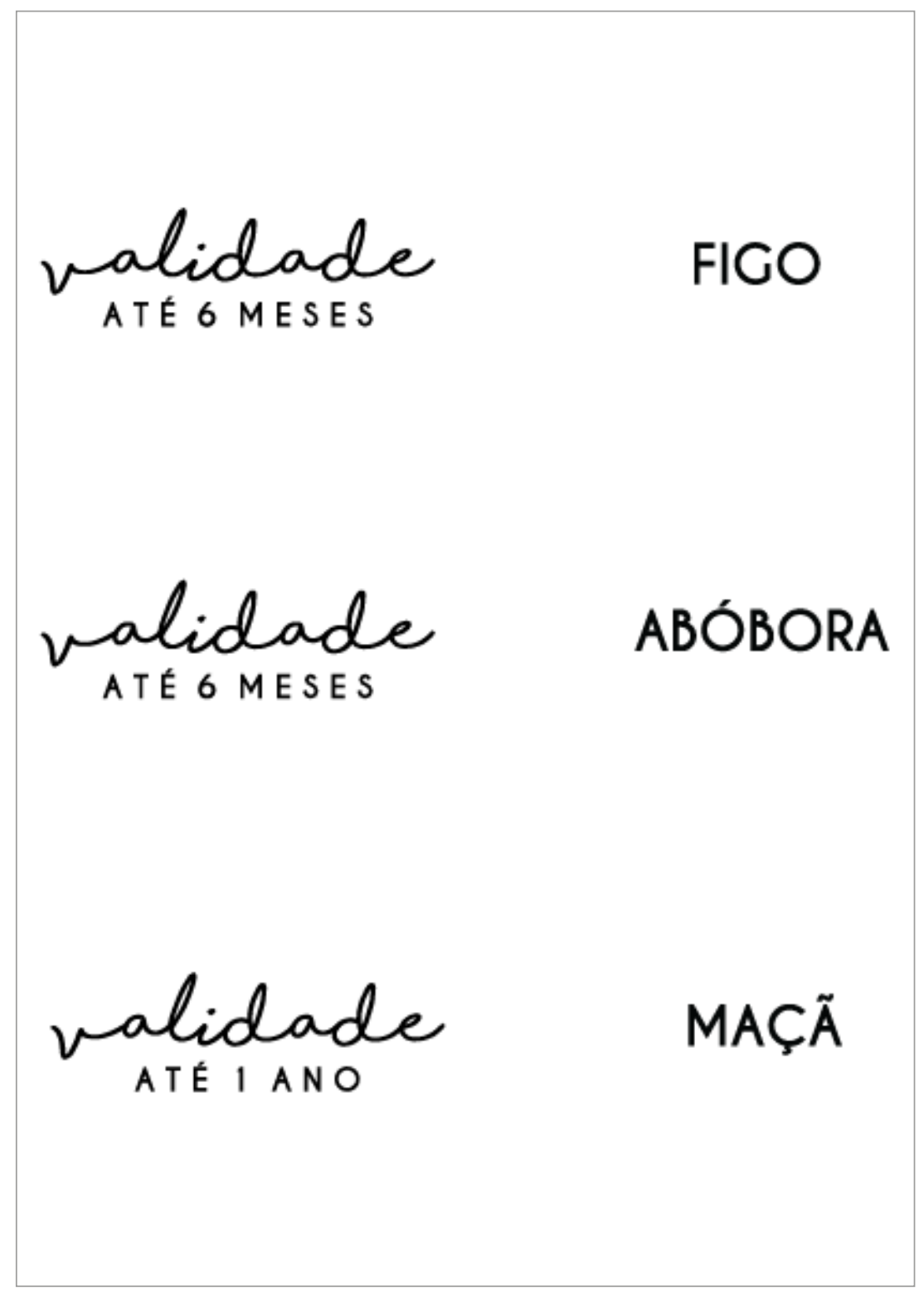

Figura 20 - Imagem Etiqueta Páginas Interiores. Fonte: Acervo da Autora.

REVISTA

ISSN: 2594-4398

D(Q)

http://periodicos.ifsul.edu.br/index.php/poliedro

221

Pelotas, RS - Brasil | v. 04 | n. 04 | p. 201 a 225 | dez. 2020

221 
Para complementar ainda a etiqueta, pensou-se em colar o tecido utilizado na tampa na parte de trás do cartão, para deixar a identidade visual bem definida e lapidada.

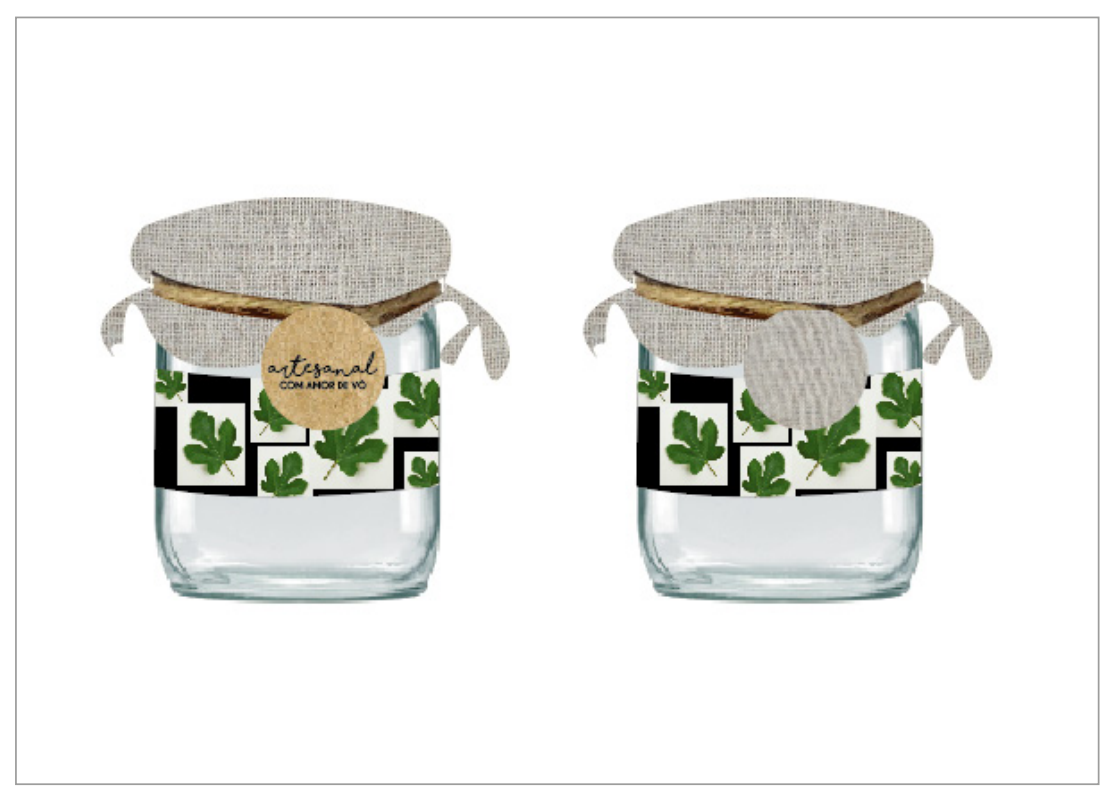

Figura 21 - Print Screen Colagem Bibi Final 1. Fonte: Acervo da Autora.

Figura 22 - Print Screen Colagem Bibi Final 2. Fonte: Acervo da Autora.
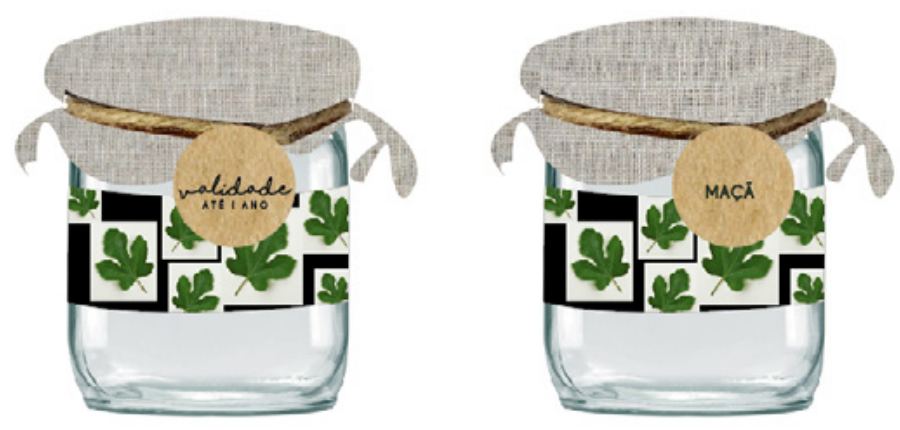
Com a Colagem Bibi finalmente completa e definida a partir de um registro e análise, percebemos que são feitas mais etapas do que se imaginou no princípio quando buscamos na lembrança definir essas etapas.

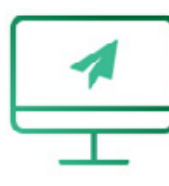

LEITURA DE BRIEFING
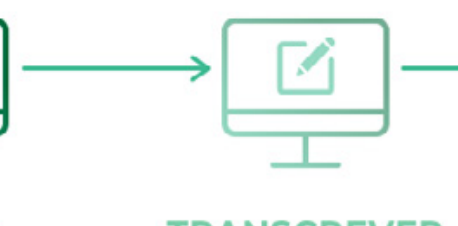

TRANSCREVER

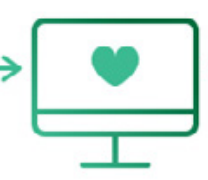

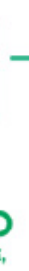

INPIRAÇÃO WEHEARTIT)

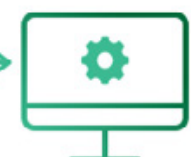

PROGRAMA A UTILIZAR

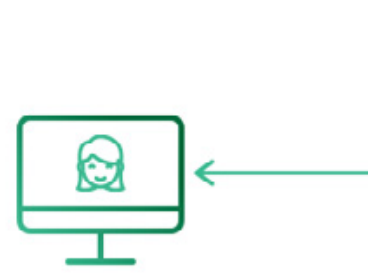

COLAGEM

BIBI
Figura 23 - Esquema a partir da definição do processo da geração de alternativa. Fonte: Elaborado pela autora (2019).

\section{CONSIDERAÇÕES FINAIS}

Esta pesquisa buscou demonstrar um novo método de geração de ideias: o método Colagem Bibi, a partir da revisão de literaturas, tanto as que explanam a respeito de outros métodos de geração de ideias, assim como também outros estudos que foram necessários serem revisados ao longo do desenvolvimento do artigo, os quais enriqueceram a natureza de informações neste.

Em um contexto geral, este trabalho acabou oferecendo duas contribuições - a demonstração de um método para a geração de alternativas e um protótipo de uma embalagem de doce caseiro -, que se deu pela forma que foi construída a análise, onde se utilizou o próprio método para elaborar essa embalagem, ainda que esta, seja ape- 
nas um protótipo, sem haver a intenção real de desenvolver uma embalagem com o resultado final, mas que acabou se assentando como um modelo.

Assim, a partir do o desenvolvimento do trabalho pôde constatar que um projeto de design é algo mais complexo do que somente preocupar-se com estética, pois expôs que cada decisão tomada e cada caminho seguido é resultado de pesquisas e de todo um conceito.

Portanto, a partir desse artigo, o método Colagem Bibi poderá ser viabilizado e utilizado por outros designers, bem como na maneira exposta aqui, ou ainda, servir de embasamento para novas propostas de configurações.

\section{REFERÊNCIAS BIBLIOGRÁFICAS}

\section{ANVISA. Perguntas View Rotulagem Nutricional.}

Disponível em: <http://portal.anvisa.gov.br/perguntasview?p_p_id=101_INSTANCE_nySyFH9AWYKL\&p_p_col_ id=column-2\&p_p_col_pos=1\&p_p_col_count $=2 \&$ _101_ INSTANCE_nySyFH9AWYKL_groupld=33916\&_101_INSTANCE_ nySyFH9AWYKL_urlTitle=rotulagem-nutricional\&_101_ INSTANCE_nySyFH9AWYKL_struts_action=\%2Fasset_ publisher\%2Fview_content\&_101_INSTANCE_nySyFH9AWYKL_ assetEntryld=417795\&_101_INSTANCE_nySyFH9AWYKL_ type=content $>$ Acesso em: 15 de julho de 2019

CALZA, M. U.; POLIDORO, M. B. Considerações sobre a geração de alternativas no design. Revista D.: Design, Educação, Sociedade e Sustentabilidade, Porto

Alegre, v. 7 n.1, 75-94, 2015.

CIARLINI, J. Brainfood, dude! Manual criativo e ilustrado de brainstorming para comunicadores organizacionais: Impresso no Brasil, 2014. 
JUST IN MIND. Low fidelity vs high fidelity wireframes:

what's the difference?. Disponível em: <https://www.

justinmind.com/blog/low-fidelity-vs-high-fidelity-wireframing-

is-paper-dead/> Acesso em: 27 de junho de 2019

MARQUES, J. B. V., FREITAS, D. D. Método

DELPHI: caracterização e potencialidades

na pesquisa em Educação. 2018

MEU ESTILO DECOR. Você sabe o que é Moodboard?.

Disponível em: <https://meuestilodecor.com.br/o-que-

e-moodboard/> Acesso em: 19 de novembro de 2019

NOBLE, I.; BESTLEY, R. Visual Research.

Editora Ava Publishing Sa, 2005

SUPER INTERESSANTE. O que era o Oráculo

de Delfos?. Disponível em: <https://super.abril.

com.br/mundo-estranho/o-que-era-o-oraculo-

de-delfos/> Acesso em: 14 de maio de 2019

WIKIPÉDIA. Mockup. Disponível em: <https://pt.wikipedia.

org/wiki/Mockup/> Acesso em: 27 de junho de 2019 